\title{
CONHECIMENTO DO ENFERMEIRO SOBRE RESPIRAÇÃO ARTIFICIAL E SENTIMENTOS GERADOS AO CUIDAR DO PACIENTE CRÍTICO EM RESPIRAÇÃO ARTIFICIAL
}

\section{Ana Flávia Bucci ${ }^{\star}$ Ana Paula Boaventura}

\section{Resumo}

Estudo transversal quantitativo que objetivou quantificar o conhecimento dos enfermeiros em ventilação mecânica. Participaram 36 enfermeiros da Unidade de Terapia Intensiva de um hospital universitário, sendo 26 (72,22\%) do sexo feminino, 14 (38,88\%) tem de 0 a 5 anos de atuação em UTI, 16 (44,44\%) possuem especialização em UTI. Em relação a participação do enfermeiro na definição dos parâmetros do ventilador mecânico junto ao médico, a participação é de apenas 2,77\%. Sobre a questão das modalidades, 33,33\% as conhecem, sendo a modalidade espontânea a mais conhecida (80,56\%). Quanto aos alarmes 94,44\% os reconhecem. Sobre ciclagem, 55,55\% responderam corretamente. Quanto as intervenções de enfermagem, destaca-se: Aspiração de tubo orotraqueal e vias aéreas superficiais; manutenção de decúbito elevado a $30^{\circ}$ que apareceram em 21,6\%. Sentimento de despreparo teórico-prático para lidar com a VM, impulsionando a busca pelo conhecimento (47\%) e Necessidade de maior interação entre equipe multiprofissional para efetividade do cuidado $(41,2 \%)$ foram os sentimentos mais relatados por estes profissionais. Conclui-se que o conhecimento geral dos enfermeiros é insuficiente, sendo preciso maior aprimoramento e treinamentos no assunto.

Palavras-chave: Respiração artificial; enfermeiras e enfermeiros; conhecimento

\section{Introdução}

O enfermeiro constitui o atendimento de primeira linha para o paciente entubado, é preciso ter conhecimento para garantir oxigenação eficaz e segura. Também é preciso competência interpessoal no ambiente da terapia intensiva, pela grande pressão para tomada de decisão e tensão pelas condições clínicas do paciente $^{1}$

\section{Resultados e Discussão}

Participaram do estudo 36 enfermeiros: 26 $(72,22 \%)$ do sexo feminino e $10(27,77 \%)$ sexo masculino. Destaca-se que: $14(38,88 \%)$ tem de 0 a 5 anos de atuação em UTI. Apenas 16 (44,44\%) possuem especialização em UTI. Conhecem modalidade de VM: 12 (33,33\%), ciclagem do VM: 20 (55,55\%).

Relacionando tempo de experiência em UTI versus acerto de modos ventilatórios, a porcentagem de maior acerto foi dos enfermeiros com até 5 anos de experiência (50\%). Em relação ao conhecimento do recurso avançado, o maior acerto veio dos enfermeiros com mais de 20 anos de atuação: 40\%. Relativo as intervenções de enfermagem, destaca-se: Aspiração de tubo orotraqueal e vias aéreas superficiais; manter decúbito elevado $30^{\circ}$ que repetiram em $21,6 \%$.

Sentimentos identificados agrupados por semelhança do conteúdo: Sentimento de despreparo teórico-prático para lidar com a VM, impulsionando a busca pelo conhecimento (47\%); Necessidade de maior interação entre equipe multiprofissional para efetividade do cuidado $(41,2 \%)$.

As ações adequadas do enfermeiro podem ser altamente resolutivas nos quadros de desconforto respiratório agudo, e prevenção dos eventos adversos. $\mathrm{O}$ enfermeiro é corresponsável pela terapia de. Através do trabalho multiprofissional e protocolos, o enfermeiro, otimiza o tratamento do paciente, reduzindo taxas como: morbimortalidade, tempo de internação prolongado e custos ${ }^{2}$.
Tabela 1. Conhecimentos do enfermeiro sobre ventilação mecânica. Campinas, $2017(\mathrm{n}=36)$.

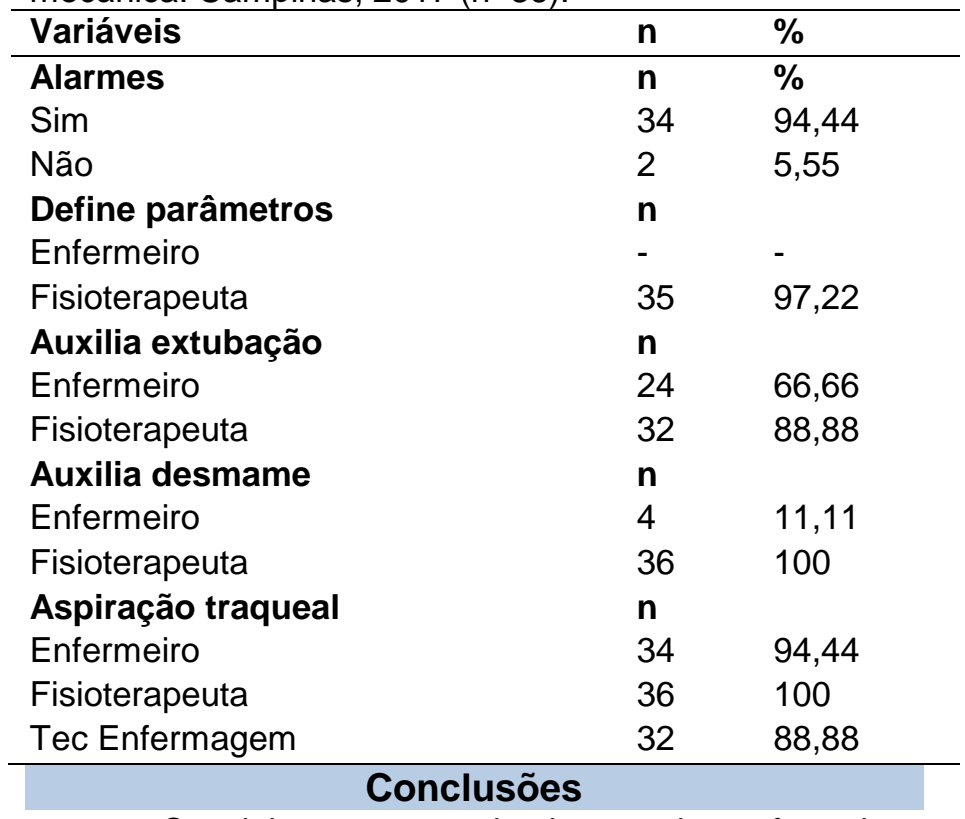

Conclui-se que o conhecimento dos enfermeiros é insuficiente e ações de educação continuada devem ser oferecidas neste sentido pela instituição de trabalho, para que o enfermeiro, ofereça um cuidado qualificado. É preciso também uma maior interação entre a equipe multiprofissional para um cuidado ao paciente em ventilação mecânica.

\section{Agradecimentos}

Agradeço ao PIBIC/CNPq pela concessão da bolsa de iniciação científica.

\footnotetext{
1 - Rocha AEF, Rocha FAAR, Neto JJMN, Gomes FMAG, Cisne MSV. Cuidado de enfermagem ao paciente ventilado artificialmente: uma revisão integrativa. Ciências da Saúde. 2017;18(1):41-53.

2 - Botha L. Level of Nurses ' Competence in Mechanical Ventilation in Intensive Care Units of Two Tertiary Health Care Institutions in Gauteng. 2012;
} 